\title{
Getting away with murder: why virtual murder in MMORPGs can be wrong on Kantian grounds
}

\author{
Helen Ryland ${ }^{1}[\mathbb{D}$ \\ Published online: 24 February 2019 \\ (c) The Author(s) 2019
}

\begin{abstract}
Ali (Ethics and Information Technology 17:267-274, 2015) and McCormick (Ethics and Information Technology 3:277287,2001 ) claim that virtual murders are objectionable when they show inappropriate engagement with the game or bad sportsmanship. McCormick argues that such virtual murders cannot be wrong on Kantian grounds because virtual murders only violate indirect moral duties, and bad sportsmanship is shown across competitive sports in the same way. To condemn virtual murder on grounds of bad sportsmanship, we would need to also condemn other competitive games. I argue, contra McCormick, that virtual murders performed within massively multiplayer online roleplaying games can be wrong on Kantian grounds when they are exploitative. Exploitation occurs when virtual murder treats the player controlling the victim in a way that they have no opportunity to consent to (i.e. as a mere means in Kantian terminology). I argue that some virtual murders involving inappropriate engagement (Ali, Ethics and Information Technology 17:267-274, 2015) and bad sportsmanship (McCormick, Ethics and Information Technology 3:277-287, 2001) are exploitative in this way and therefore also wrong on Kantian grounds.
\end{abstract}

Keywords Virtual murder $\cdot$ MMORPGs $\cdot$ Kantian Deontology $\cdot$ Exploitation

\section{Introduction}

When we talk about virtual murder, we are typically referring to the sort of act which Morgan Luck defines as follows:

A player commits an act of virtual murder in those cases where he directs his character to kill another in circumstances such that, were the game environment actual, the actions of his character would constitute actual murder (Luck 2009, p. 31).

There are two ways to unpack this definition: in terms of the constitution of murder and in terms of the game environment.

In terms of constitution, Luck's definition suggests that, for any act of virtual murder, there can be a possible realworld counterpart. This allows us to say two things. Firstly, 'virtual murder' is an umbrella term that accommodates a variety of virtual acts, such as assassination, homicide, and

Helen Ryland

hxr341@student.bham.ac.uk; hryland1989@gmail.com

1 University of Birmingham, Birmingham, UK genocide. Secondly, just as every act of actual killing is not an act of actual murder, there will be acts of virtual killing that are not virtual murders. For example, virtual killings that arise from just war, self-defence, or accident would not constitute a virtual murder.

What virtual murder entails depends on whether the virtual murder takes place in a single player or multiplayer game environment. In single player games, a player can only commit virtual murder if they direct their character to kill a non-playable character or a computer-generated character. Examples include purposefully running over a pedestrian in Grand Theft Auto or 'accidentally' setting fire to a sim in The Sims. In multiplayer games, a player can also commit virtual murder by directing their character to kill another player's character. An example would be killing another player's character's in World of Warcraft to steal that character's possessions. Whilst virtual murders performed in multiplayer games can be directed against both computer-generated characters or other players' characters, I will examine the latter case in this article.

Although interesting moral arguments can be made about virtual murder in either game context, I will focus on virtual murders performed in multiplayer games, specifically 
on those enacted in massively multiplayer online roleplaying games (hereafter MMORPGs) such as World of Warcraft and Second Life. Such games feature real players interacting with other real players through the medium of virtual avatars and virtual actions. It is this dichotomy between the real and the virtual that raises the question of whether an entirely virtual act-virtually murdering another player's avatar-constitutes a real moral wrong.

For those who support the so-called magic circle arguments, the answer to this question is a definitive 'no'. In Homo Ludens, Huizinga (1949) argued that games are demarcated from real-life in the sense that gameplay takes place within a 'magic circle'. Inside this magic circle, the game environment has its own rules and norms which temporarily replace those of the real-world. For example, when playing rugby, it is permissible to tackle another player to the ground. As long as one is playing the game, this norm (tackling is acceptable) supersedes real-life rules (whereby 'tackling' would constitute physical assault). Numerous theorists have applied Huizinga's magic circle to video games in order to determine whether virtual game actions can be assessed in relation to real-world moral codes (Craft 2007; Kim and Werbach 2016; Ostritsch 2017). Those who support the magic circle argument argue for a form of amoralism, whereby virtual actions take place within the magic circle and are thus performed in a space which is separate to the real-world and exempt from real-world moral judgements. ${ }^{1}$ On this view, no act of virtual murder is wrong because no virtual actions (within games) can be morally evaluated.

The remainder of this article argues against the magic circle views by arguing that some virtual murders in MMORPGs are morally wrong, on Kantian grounds. I argue for this position in four sections. Firstly, I discuss the features of MMORPGs_-being massively multiplayer, being online, involving roleplay, and being games-in order to explain why MMORPGs are morally evaluable. Secondly, I consider arguments by Ali (2015) and McCormick (2001) which support the idea that some cases of virtual murder are objectionable, but not necessarily morally wrong. Thirdly, I expand on these arguments to argue that some virtual murders in MMORPGs are wrong, on Kantian grounds, when they involve exploitation. Exploitation will occur when the virtual murder treats the player controlling the victim in a way that they have no opportunity to consent to. I explain how this exploitation is shown in both cases of inappropriate engagement (Ali 2015) ${ }^{2}$ and bad sportsmanship

\footnotetext{
${ }^{1}$ Such amoralism has been evaluated by Dunn (2012, pp. 356-362), Ostritsch (2017, pp. 117-118), and Young (2013, pp. 6-7; 15-18).

2 'Inappropriate engagement' is explained in more depth in the "Why virtual murder can sometimes be wrong" section. In essence, it refers to players not engaging with the game in the way that the game creators intended.
}

(McCormick 2001). Finally, "The social roles objection" section defends this view against the social roles objection, which states that victims $d o$ tacitly consent to the virtual murder. This challenges my claim that the act of virtual murder treats victim players as mere means by involving an exploitative lack of consent. I argue that the social roles objection is unsuccessful.

\section{The moral status of MMORPGs}

MMORPGs have four main features: they are massively multiplayer, they are online, they involve roleplay, and they are games. ${ }^{3}$ This section discusses how each of these features makes MMORPGs morally evaluable.

\section{Massively multiplayer}

"To the extent that our game play puts us in contact with agents who are either rational or sentient, it is the proper subject of moral evaluation" (Patridge 2011, p. 303).

In the above quotation, Stephanie Patridge pinpoints the very simple reason why the 'massively multiplayer' element of MMORPGs makes them morally evaluable; other people are involved in the game. When we use our avatars to interact with other avatars in a MMORPG, we are typically interacting with other real people - the other gamers controlling the avatars. As we generally accept that other real people are moral agents, it seems feasible to suppose that our virtual interactions with other real people are, at least in principle, morally evaluable.

Yet, if the 'magic circle' arguments of the introduction are correct, Patridge's claim is false. On the magic circle view, all agents involved in game play are within the magic circle, and beyond moral evaluation. In other words, the presence of other people does not automatically make a game morally evaluable. This is because the other people are game players and actions performed towards these other game players are game actions. On the magic circle view, games exist in their own world with independent rules and

\footnotetext{
${ }^{3}$ Some might object that 'massively multiplayer' refers to two features rather than one, i.e. there is massiveness alongside a multiplayer element. This is technically true, but I will consider both elements together as (a) no part of my argument relies on the notion of 'massiveness' so there is no dialectal need to give massiveness a separate discussion and (b) as massiveness and the multiplayer element are connected, considering them separately would likely necessitate repetition. For our purposes it is sufficient to state that 'massiveness' refers to the scale of the multiplayer element of MMORPGs. For example, according to a survey by Statista (2015), there were 5.5 million players of World of Warcraft in 2015.
} 
norms, so game actions cannot be evaluated from external (real-world) moral vantage points.

To argue against the above, and show that the 'massively multiplayer' element of MMORPGs is morally evaluable, we need to extend Patridge's claim to explain how game actions performed against other players can transcend the magic circle. One way of doing this is to argue that, when other real people are involved, virtual actions have a necessary and systematic connection with the real world. Regardless of how fantastical or fictionalised the action or text of the virtual interaction is, the underlying nature of the interaction [(typically) real-time communication between persons] is real. For this reason, we can classify MMORPGs as what Dunn (2012), drawing on the arguments of Edward Castronova, calls 'open game worlds'. On Dunn's definition, open game worlds are extensions of the real world and, consequently, actions performed within open game worlds matter, both psychologically and morally (Dunn 2012, p. 256). MMORPGs are open game worlds because the presence of other real people means that virtual actions, such as virtual murder, can go beyond the game world to have a moral and psychological impact on real people (the other gamers). ${ }^{4}$

At this point my opponent might object that Dunn's 'open game worlds' does not do enough to avoid the magic circle arguments. This is because we have yet to explain how virtual actions have a moral impact on real people (the other gamers). One option would be to accept a consequentialist view, whereby virtual actions impact real people (the other gamers) if they have real-world consequences, such as causing psychological distress (Dunn 2012; Wolfendale 2009). This view, however, does not avoid the magic circle arguments. A defender of the magic circle view could argue that all the consequentialist argument shows is that the player experiencing psychological distress is playing the game in the wrong way; they are overinvested and/or are poor losers. ${ }^{5}$ This is not enough to show that the game action (virtual murder) is wrong.

For the remainder of this article I will argue that virtual murder is wrong when it exploits the player controlling the virtual murder victim. ${ }^{6}$ In the "How virtual murder can be exploitative" section, I will argue that virtual murder is exploitative if the victim player has no opportunity

\footnotetext{
4 A similar argument is presented in Driver's (2007) 'Dream Immorality'. Driver argues that, for a non-veridical action to be immoral, said action must track reality and systematically connect to real-world consequences.

5 For a discussion of emotional overinvestment, see Wolfendale (2009, pp. 9-10).

${ }^{6}$ Existing literature concedes that a virtual action is objectionable if it harms or wrongs a real person (Ali 2015; McCormick 2001; Ostritsch 2017; Wolf 2003). I contribute a new dimension by focusing exclusively on the harms generated by exploitation.
}

to consent to the act. ${ }^{7}$ This will happen when the virtual murder is a supposedly forbidden action, is of ambiguous permissibility, and/or is purposefully performed on players who do not (yet) know the rules of the game. ${ }^{8}$ In these cases, I argue that such virtual murders are wrong both within the magic circle (as they typically violate game norms) and outside the magic circle (as, because the victim player has no opportunity to consent to the act, a real person (the victim player) is being treated as a mere means). The remainder of this section will explain how the other features of MMORPGS- being online, involving roleplay, and being gamesenable such exploitation, allowing some virtual murders to be wrong. ${ }^{9}$

\section{Online}

The online nature of MMORPGs will necessarily affect how we understand this moral wronging claim. On the one hand, moral wronging seems to be made easier in the online world than in the real world. This is at least partially due to the anonymity found in online spaces [see McCormick (2001) and Danielson (1992)]. For example, when I interact with you in a MMORPG, you encounter me as a fictionalised avatar; my actual identity remains hidden. As McCormick (2001, pp. 282-283) explains, this anonymity can sometimes encourage users to act in ways that they would not condone in the real world. In MMORPG settings, this can range from using insulting,

\footnotetext{
7 Other examples of exploitative acts in MMORPGs include interfering with other players by freezing their movements, relocating them to another place, or otherwise disrupting their game plans for its own sake. I will not consider these other forms of exploitation further as my focus is on how virtual murder, as an exploitative act, can be wrong; not whether virtual acts in general can be exploitative. However, this being said, it is worth noting that an upshot of my argument will be that, if virtual murder can be morally objectionable because it is exploitative, then other virtual acts that are exploitative in the same way (by being acts that players have no opportunity to consent to) will also be morally objectionable. My arguments can therefore be extended beyond virtual murder. I thank an anonymous reviewer for this point.

${ }^{8}$ There are virtual murders which do not involve these features and are not exploitative. For example, virtual murders that are permitted game actions and which are performed on players who know the rules of the game. Such non-exploitative virtual murders are not wrong on my account. This does not damage my argument as my focus is on showing that some virtual murders are wrong when they are exploitative.

${ }^{9}$ As it is only the 'multiplayer' nature of the game which is necessary for exploitation, we could just as easily focus on morally evaluating exploitation in any multiplayer game. For the purposes of this article, I am restricting the scope to examining one type of exploitation (virtual murder) in one type of multiplayer game (MMORPGs). This is because MMORPGs seem to be the most salient fora for, and virtual murder a strong form of, the kind of exploitative wronging I am concerned with. Thanks to an anonymous reviewer for this point.
} 
discriminatory slurs to simulating immoral actions, such as virtual rape.

On the other hand, there is ongoing debate regarding how seriously we should take these online wrongs. At least in the case of game actions, it seems clear that online wrongs are not as wrong as their real-world counterparts. In saying that virtual murder is wrong, we are not saying that it has the same moral (or legal) status as realworld murder. And yet, as the last subsection indicated, there does seem to be something wrong with some virtual murders.

This difficulty with determining the moral status of online actions has been well discussed by Young (2015). Young begins by stating that moral judgements "...form the basis for rules which have their own objective status within the socially constructed space they occupy" (p. 318). For example, we know that actual murder is wrong because, in the real-world, there is general consensus that murder possesses various wrong-making properties. Conversely, Young argues that it is less clearcut that virtual murder is wrong because virtual murder takes place in a new socially constructed space (the online world) whose moral rules are open to debate. Young thus seems to claim that, in order to say that virtual murder is wrong, we would need to agree what wrong-making property virtual murder has, and that the presence of this wrong-making property justifies taking a disapproving attitude towards virtual murder. If we can get consensus on this disapproval, then we can create a moral norm or code for virtual murder (pp. 318-319).

In what follows I will argue that virtual murder is wrong because it violates a genuine moral requirement. I will agree with Immanuel Kant that there is something intrinsically wrong with treating a person as a mere means, as happens in cases of exploitation where we treat a person in a way that they have no opportunity to consent to. In other words, I accept that there is a certain code of conduct (never treat persons as mere means) that ought to be followed; if this code is violated, one has acted immorally.

From this I will argue that, when virtual murder does violate a moral code in this way, the correct response is to morally condemn these virtual murders. In this sense, I am adopting the strong response to online wrongness promoted by Waddington (2007). Waddington argues that, when a virtual game action violates a moral code, we must condemn the action because, to fail to do so would be "... to devalue...the very idea of wrongness." (Waddington 2007, p. 128). In accepting this view, I am suggesting that, whilst virtual murder is not as wrong as actual murder, it is nevertheless really wrong in the sense of violating a real-world moral code in an online space.

\section{Roleplaying}

At this point, some might object that the roleplaying nature of MMORPGs prevents the gamer from actually ever violating a moral code when they perform a virtual murder. A specific variant of this objection will be considered in "The social roles objection" section. For now, though, we can present the objection more generally as follows. Gamers play certain roles in MMORPGs and, on the basis of these roles, certain game actions, such as trash-talking, violence, or perhaps even virtual murder, become permissible (at least within the world of the game). This is because the game role somehow justifies the performance of otherwise immoral acts. For example, suppose that our gamer is playing an apocalyptic fantasy MMORPG. Her avatar is a bounty hunter tasked with killing members of a rebel group who are committed to the destruction of civilisation. In this case, it does not seem like the gamer violates a moral code when she virtually murders avatars who belong to members of the rebel group. Her role as bounty hunter seems to give a morally exempting reason for performing virtual murder.

The above objection thus depends on the idea that, by taking on a certain character, the gamer's actions are mitigated by some narrative element of the game's storyline. In this sense, gamers are viewed as analogous to actors; both the actor and the gamer are not morally responsible for actions performed when in-character [see Ostritsch (2017) and McCormick (2001)] and so they never commit a wrong (within these roleplay spaces).

This claim - that roleplaying neutralises moral responsibility-has, however, recently been challenged by expressivist arguments. The basic expressivist claim, here explained in terms of Bartel's (2015) arguments, is that a violent act in a video game can sometimes be morally wrong (even if it is scripted and determined) if it reflects the will of the player (i.e. what they actually desire to do). In these cases of willing participation, an otherwise permissible virtual murder becomes wrong because it expresses an immoral attitude on the part of the player. To see this, we can consider an example presented by Patridge (2013) in which "a game might invite us to virtually hunt down and lynch characters that appear to be of African descent" (p. 33). Unlike the previous bounty-hunting example, this lynching example does not provide a justifying reason to perform virtual murder. This is because, as Patridge explains, there seems to be something morally wrong about a gamer willingly adopting the role of a lyncher. This is because, in adopting this role, the gamer must engage with the game in a way that supports immoral viewpoints, i.e. that racism and genocide are 'fun' (ibid). In these cases, the virtual game action seems to transcend the amoral realm of the magic circle because the game action itself violates a real-world moral code (promoting racism, genocide, etc.) 
The remainder of this article will focus on virtual murders which also transcend the magic circle by violating real-world moral codes. Using the arguments of Ali (2015) and McCormick (2001) as a touchstone, I will explain how some virtual murders in MMORPGs involve, respectively, inappropriate engagement and bad sportsmanship. I then develop these arguments to argue that such cases do not simply show bad gaming practice, they involve a form of exploitation that violates real-world moral codes (in this case Kant's formula of humanity).

\section{Games}

To argue for the above, I will be accepting that the 'games' element of MMORPGs is itself morally evaluable. To do this, I draw on Ostritsch's (2017) claim that "games themselves can be morally problematic, viz. when they do not only represent immoral actions but endorse a morally problematic viewpoint" (p. 117). In other words, I am claiming that MMORPGs are not morally evaluable simply because they allow for virtual murder, but because they are the sort of game that allows for virtual murder to be performed in morally objectionable ways (in this case, as a form of exploitation) [see Goerger (2017) and Ostritsch (2017)].

To reiterate the above arguments, I will claim that some virtual murders in MMORPGS are morally evaluable because they can wrong other real persons and, in doing so, violate real-world moral codes. In the next section I will provide the foundations for this argument by considering Ali's (2015) and McCormick's (2001) moral evaluations of virtual murder. The "How virtual murder can be exploitative" section will expand on these arguments to show how both can be used to support the claim that virtual murder is wrong on Kantian grounds of exploitation.

\section{Why virtual murder can sometimes be wrong}

In opposition to standard claims that virtual murder is not impermissible (see Luck 2009), Ali (2015) and McCormick (2001) both accept that virtual murder can, in some cases, possess wrong-making features. This section will summarise their arguments, before explaining how both arguments can be extended in order to account for the particular wrongness of virtual murders performed within MMORPGs.

\section{Ali (2015): inappropriate engagement}

Rami Ali's argument begins with the claim that to understand the moral significance of virtual game actions, we need to look at how players are engaging with the game (p. 269). As an expressivist, Ali suggests that we assess engagement by observing whether gamers are willingly acting out immoral game narratives (p. 272) or are using the game to roleplay immoral fantasies (pp. 269, 274). Ali argues that both of these are cases of inappropriate engagement, but for our purposes it is the latter example-using the game to roleplay immoral fantasies - that is particularly interesting as it focuses on ways in which players can use a game in morally objectionable ways.

Ali focuses on cases where "...gamers use the game and the available actions for their own ends, not for the ends that are specified by the game" (p. 271). He gives the example of a gamer playing a sports game in order to enjoy the scenery; in this case the gamer is not playing the game in the correct way. As Ali highlights, this issue of using the game in the wrong way is particularly problematic in games which lack a defined narrative, and which make deviance from the proper game aim even easier (p. 273). For example, Call of Duty allows for the game narrative to change based on the player's choices. On Ali's definition, a gamer would show inappropriate engagement if they were to use modded content in order to alter the possible narratives so as to give their character a particular advantage, or to perform unscripted immoral acts. As Ali explains, these modified/deviant game actions cannot be morally permissible "...if their only pretext is enjoying the freedom and performance of these acts" (p. 273). We can apply this to our virtual murder case as follows. A virtual murder may be permissible if it is performed as part of a non-objectionable game narrative. However, on the inappropriate engagement view, a virtual murder can become impermissible if the gamer uses the game to perform a virtual murder that (a) goes against the game narrative and (b) is performed because the gamer wants to perform the act.

Ali's argument can, therefore, be summarised as the claim that some virtual murders are wrong because the gamer is performing virtual murder in the wrong way. Namely, the gamer is choosing to perform a virtual murder and, in doing so, are using the game in a non-standard way. Ali's argument is thus limited to chastising the gamer performing the virtual murder because their desire to perform virtual murder reflects an immoral, non-innocent fantasy. This is an important point to make, but I argue that Ali's claims can be extended further. In the "How virtual murder can be exploitative" section I will explain how inappropriate engagement in MMORPGs typically involves the exploitation of other players. In this sense, virtual murder is wrong not only because the gamer performing the virtual murder has chosen to perform the murder, but because, in making this choice, the gamer controlling the virtual murderer necessarily exploits the gamer controlling 
the virtual victim by acting in a modified/deviant way that they have no opportunity to consent to.

\section{McCormick (2001): bad sportsmanship}

Like Ali, McCormick accepts that we can determine the moral status of virtual game actions by examining how players (in our case, the player controlling the murderer) engage with the game. Where McCormick differs to Ali is in his use of a Kantian framework to assess game engagement (pp. 282-285). Specifically, McCormick focuses on Kant's formula of humanity: "So act that you use humanity, in your own person as well as in the person of any other, always at the same time as an end, never merely as a means" (Kant 2012 [1785], IV: 429, 10-12). McCormick correctly explains that, on Kant's view, to treat persons morally, we must recognise their status as autonomous, rational agents (or ends, in Kantian terminology). If we fail to grant this recognition, we treat a person as a mere means (McCormick, p. 282). Using this definition, McCormick argues that one way to treat a person as a mere means is to act violently towards them. This is because when we perform violent acts, we objectify the victim as something to be used (ibid). He then considers whether this argument can be transferred to the virtual world - do violent game actions (such as virtual murder) in MMORPGs cause persons to be treated as mere means?

In response to this question, McCormick argues that violent game actions in MMORPGs do treat persons as mere means when they involve bad sportsmanship. In competitive games, the winner will be a bad sport if they are disrespectful or insulting to the loser, whereas the loser will be a bad sport if they demean the achievements of the winner (p. 282). McCormick argues that what is wrong in both of these cases of bad sportsmanship is that the player is overly concerned with their own experiences (winning/losing) and fails to acknowledge the autonomous goals of the other player (p. 282).

McCormick's argument thus presents one way in which we can assess virtual murder in MMOPRGs using a Kantian framework. On McCormick's view, if a virtual murder shows bad sportsmanship then it will violate the formula of humanity by treating a person as a mere means. Interestingly, whilst McCormick does accept that virtual actions can be assessed in this way, the remainder of his argument is concerned with showing why virtual actions which show bad sportsmanship are not, in fact, wrong on Kantian grounds. He offers two arguments for this view.

Firstly, McCormick argues that bad sportsmanship is not a notable moral wrong. He claims that "... while being a bad sport is not a very serious moral crime for Kant (it is not murder, after all), he would say that one should strive to be a good sport" (p. 282). In this sense, McCormick seems to shift from talking about bad sportsmanship in terms of morality (one ought not be a bad sport) to talking about it in terms of appropriate behaviour (if one wants to play the game properly, one ought to develop the right character). In other words, McCormick is saying that bad sportsmanship is undesirable rather than wrong. McCormick justifies this argument by stressing that bad sportsmanship is possible in all competitive games, such as football, boxing, dominoes etc (pp. 282-283). As, on McCormick's view, there is nothing special about the bad sportsmanship shown in video games, he argues that all cases of bad sportsmanship would have to be treated equally. If an action in a video game is wrong because it shows bad sportsmanship, we would have to also say that actions in dominoes or rugby are wrong because they show bad sportsmanship. As McCormick argues, this would condemn far too many games as being morally wrong. For this reason, he concludes that good sportsmanship can only be a recommendation rather than a moral requirement (p. 283).

Secondly, McCormick argues that the only type of moral duty that is violated in virtual gaming cases are indirect moral duties, and the violation of these indirect duties is insufficient to show that an action is wrong (p. 283-284). McCormick defines indirect duties as the duties we have to not perform certain actions, not because they are wrong per se, but because performing these actions increases the likelihood that we will violate our direct duties to others (ibid). To explain this further, McCormick suggests an analogy between our treatment of animals and our treatment of virtual avatars (p. 283). He explains that, on Kantian grounds, we have an indirect duty to not harm animals because there is a risk that, by harming animals, we will become indifferent to pain and suffering and will consequently be more likely to mistreat other humans. By parity of reasoning, McCormick suggests that we have an indirect duty to not perform violent game actions because, by performing these actions, we become indifferent and may consequently be more likely to be violent to others in the real world. ${ }^{10}$ McCormick then states that violating such indirect duties (for example, by performing a violent game action) is insufficient to show that that action is wrong, on Kantian grounds (p. 284). To justify this claim, McCormick focuses on Kant's statement that certain actions, such as butchery and surgery, violate indirect duties to not harm but are nevertheless not wrong. This is because these activities benefit society in a way that outweighs their negative side effect: that the butcher and surgeon might become indifferent to pain and mistreat others

\footnotetext{
$\overline{10}$ McCormick's argument has some similarities to Ali's inappropriate engagement view. Both argue that a violent game action can be wrong when, in performing the action, the gamer displays an inappropriate or immoral attitude (e.g. that murder is fun).
} 
(ibid). McCormick argues that the same can be said about virtual game actions: their benefits (enjoyment) seem to outweigh their potential negative side effects (generating indifference). In this sense, whilst virtual murder does violate indirect moral duties, it is not wrong on Kantian grounds. ${ }^{11}$

In the "How virtual murder can be exploitative" section I will argue that McCormick is incorrect to suppose that virtual murder in MMORPGs cannot be wrong on Kantian grounds. Contrary to McCormick's claims I will explain how there is a difference between the bad sportsmanship shown in MMORPGs and the bad sportsmanship shown in other competitive games. The former but not the latter involves a type of immoral exploitation. By focusing on exploitation, I will argue that what is wrong with virtual murder is not that it increases the risk that we will mistreat others in the future, but that it mistreats the player controlling the victim now. By exploiting the player controlling the victim, we treat them in a way that they have no opportunity to consent to. As this exploitative treatment violates the formula of humanity, virtual murder can be wrong on Kantian grounds.

\section{How virtual murder can be exploitative}

The last section suggested that we can expand the arguments of both Ali (2015) and McCormick (2001) by bringing in the concept of exploitation. On my view, a virtual murder will be wrong (on Kantian grounds) if it violates the formula of humanity by treating the player controlling the victim as a mere means. This will happen in cases of exploitation where the player controlling the victim has no opportunity to consent to the virtual murder. In this respect, my thesis agrees with Ali and McCormick that some virtual murders are objectionable, but brings in elements that their accounts miss. I emphasise the wronged party to a greater extent (the player controlling the virtual murder victim), and identify the kind of wrong done to them (virtual murder exploits them by treating them in a way that they have no opportunity to consent to). Below, I will present some cases of virtual murder which are exploitative because the player controlling the victim has no opportunity to tacitly consent to the virtual murder. I will explain how some cases of inappropriate engagement (Ali) and bad sportsmanship (McCormick) are good examples of these exploitative virtual murders. ${ }^{12}$

As Pallikkathayil (2010) explains, tacit consent occurs when " ...just by acting in a certain way, one changes the permissions others have whether or not one wants those permissions to change and would refuse to endorse the change if asked" (p. 127). For example, strangers are not (typically) permitted to observe me by staring through the windows of my (private) house. However, when I leave my house and enter a public space, strangers are permitted to observe me, even if I would not agree to being observed. In other words, I have made a choice (to leave my house) and in choosing this action I tacitly consent to others behaving in certain ways towards me, even though I would not explicitly consent to their actions if asked.

As Wolf (2003, p. 1) implies, tacit consent seems particularly relevant to virtual murder. This is because engaging with a virtual game is an entirely optional act, so all gamers choose to play a certain game and/or to continue playing a certain game. As MMORPGs are multiplayer environments, when a gamer chooses to play a MMORPG they voluntarily place themselves in a situation which allows others to interact with them (ibid). Using our definition of tacit consent, we could make the following claim: victims make a choice (to play a MMORPG) and in choosing this action they tacitly consent to others behaving in certain ways towards them, even though they would not agree to their actions, if asked. In this way, victims may tacitly consent to virtual murder.

Intuitively, the above does seem to provide a strong argument against the impermissibility of virtual murder: by choosing to play a violent MMORPG at all, victims must necessarily consent to all violent acts, including their own virtual murder. However, I argue that the tacit consent view is actually not strong enough to demonstrate the permissibility of virtual murder. This is because, for tacit consent to make virtual murder permissible, the tacit consent must involve a level of awareness of background norms and moral standards. As I will argue below, there are cases of virtual

\footnotetext{
12 Note that there may be cases of wrongful murder in MMORPGs which are neither bad sportsmanship nor inappropriate engagement. This would not undermine my argument. I am concerned with showing how virtual murders in MMORPGs can be exploitative when the victim player has no opportunity to consent to the act. Below I will explain how this is shown in many cases of inappropriate engagement and bad sportsmanship, and other cases where tacit consent is missing. I am referencing cases of inappropriate engagement and bad sportsmanship as they seem to be good examples of the exploitative treatment that I am interested in.
}

11 This line of argument has been challenged by David I. Waddington (2007, p. 125). Waddington explains that the reason Kant condones the actions of butchers and surgeons, in spite of them violating indiharm that they perform is a necessarily evil. Waddington points o that virtual game actions do not have this same status. They are not necessary evils. The gamer performs a violent/harmful action because they choose to; gamers do not have to play video games, and video games do not have to feature violent actions. As such, Waddington argues that McCormick's arguments on the justifiability of indirect harms does not extend to virtual game actions. 
murder where this awareness is missing, and where it is not possible for tacit consent to be suitably informed. ${ }^{13}$ Because of this, the virtual murder will be exploitative in such cases.

Above I suggested that, to tacitly consent to virtual murder, victims must have an awareness of how their action (playing the game) relates to relevant norms and moral standards (the permissibility of virtual murder). In what follows I will argue that there are three main ways in which this awareness can be lacking from virtual murder cases.

The first way in which victims could fail to tacitly consent to virtual murder is if virtual murder is supposedly a forbidden action, according to the rules of the game. There are two main ways in which we can present this idea. Firstly, suppose we take a game in which there is a blanket rule preventing all virtual murder. In such games, if a virtual murder is performed, it is an illegitimate action. As the virtual murder would not be an intended game action, this would be an example of both Ali's inappropriate engagement, and an act where the victim player has no opportunity to give tacit consent. Secondly, we might suppose that, whilst other acts of virtual killing and combat are permissible, certain types of virtual murder are implicitly forbidden. An example of this would be the so-called team killing murders performed in games such as Playerunknown's Battlegrounds. In team killing scenarios, victims are invited to join an existing group of players to complete a quest. Once the quest is complete, and victims have fulfilled their purpose, victims are murdered by members of their own team (Chalk 2017). In cases where virtual murder is supposedly forbidden, it is clear that victims cannot tacitly consent to the virtual murder. This is because it is reasonable for victims to assume that their action (playing the game) relates to the background norm that virtual murder is impermissible.

The second way in which victims could fail to tacitly consent to virtual murder is if the moral standard related to virtual murder is ambiguous. Again, there are two ways in which this could happen. Firstly, the game may lack an explicit code of conduct and/or fail to offer any explicit consideration of the act of virtual murder. This may happen in cases where the act of virtual murder is not an original game action, but one that has been developed as a result of a hack or modification. Many of these 'modification' cases would be an example of Ali's inappropriate engagement. Secondly, it may be that, whilst virtual murder is permissible, it is not clear whether it is permissible in all game contexts. An example of this type of ambiguity is discussed

\footnotetext{
13 I am not saying that it is impossible for a player to give informed consent to virtual murder in general. I am saying that, in the cases described below, it is incoherent to suppose that the victim player gives informed consent. This is because, in such cases, the actions of the murderer player prevent the victim player from having the opportunity to consent to the act of virtual murder.
}

by Mason (2014, pp. 1115-1117) in relation to a 2006 World of Warcraft case in which a gamer died and her virtual guild held an in-game funeral for her avatar. During the funeral a rival guild appeared and massacred all those attending. As Mason explains, there is some debate as to whether a virtual murder performed in a non-combat funeral setting is permissible. As long as this ambiguity is present, it is typically not the case that victims tacitly consent to virtual murder. This is because, as background moral standards are open to interpretation, it is unclear how the victim's actions (playing the game) link to these interpretable standards. Tacit consent can, again, not be fully informed.

Finally, victims could fail to tacitly consent to virtual murder if they are not aware of the norms and moral standards of the game. In other words, the victim does not know that virtual murder is a possible action. As Simon Carne explains, this is typically shown in so-called “... Newbie-killing [purposefully killing new players who have not learned how to play the game]..." (Carne in Wolf 2003, p. 70). In these cases, whilst the virtual murder may be a permissible action, it is still not feasible to suppose that victims tacitly consent to the virtual murder. This is because, by not knowing what game actions are possible and/or permissible, the victim cannot know how their action (playing the game) links to (currently unknown) norms and moral standards. ${ }^{14}$ This third type of virtual murder may be an example of McCormick's bad sportsmanship. This is because the player controlling the murderer is purposefully exploiting the player controlling the victim's lack of knowledge, and is acting in a way that ignores the victim player's autonomous goals.

What the above suggests is that, for victims to tacitly consent to virtual murder in a way that would make the act permissible, they must have a full and definitive understanding of how and when virtual murder is permissible. If correct, the above discussion presents three ways in which this tacit consent could be missing in virtual murder cases. Some virtual murders can be wrong because they are forbidden, of ambiguous permissibility, or an opportunistic exploitation of victims' lack of knowledge. As argued above, many of these morally wrong virtual murders will also be examples of inappropriate engagement (Ali) and/or bad sportsmanship (McCormick).

\footnotetext{
${ }^{14}$ I take it that a player will know that virtual murder is a possible action if they know that virtual murder could happen within the game. To know this, I do not think that a player would need to know all possible virtual actions within the game (i.e. every conceivable move or action that another player could perform against them). As footnote 16 explains, this would be an overly demanding requirement and related more to explicit consent than tacit consent. I thank an anonymous reviewer for suggesting this clarification.
} 
In the examples discussed, because victims do not have a clear understanding of the moral standards regarding the permissibility of virtual murder, victims cannot tacitly consent to virtual murder. Due to this absence of tacit consent, the virtual murders discussed above exploit the player controlling the victim by treating them in a way that they have no opportunity to consent to (in other words, it treats them as mere means). As this exploitative treatment violates Kant's aforementioned formula of humanity, these virtual murders are wrong on Kantian grounds. The next section will defend this view against the social roles objection. ${ }^{15}$

\section{The social roles objection}

The social roles objection challenges the idea that, in cases of potential exploitation, victims have not consented to the 'exploitative' act. It does this by arguing that, in most cases of apparent exploitation, victims have agreed to play a social role. In accepting this social role, victims have tacitly consented to otherwise impermissible treatment that results from their social role (see Young 2013, pp. 40-41; Parfit 2011, pp. 212-232). As victims have given tacit consent, the act does not treat them as mere means; they are treated simultaneously as a means and an end.

In this sense, the social roles objection implicitly challenges my definition of tacit consent. I argued that a victim will tacitly consent to virtual murder if, and only if, they are aware of how their action (playing the game) relates to background norms and moral standards concerning the permissibility of virtual murder. The social roles objection can be used to challenge this definition by claiming that the relevant action is not simply playing the game, but playing the game whilst playing a specific social role (to be defined below) which exempts certain treatment from being exploitative.

Indeed, the social roles objection works particularly well when applied to games and competitive sport. For example, consider the exploitative act of my punching you in the face in order to reduce my stress levels. As this act is neither legitimate nor anticipatable you, as the victim, cannot tacitly consent to my punching you in the face. My action treats you

\footnotetext{
15 As discussed above, Kant's formula of humanity argues that it is impermissible to treat a person as a mere means. This initially seems to prohibit a number of everyday actions, namely those that involve us using a person in order to get something, e.g., using a salesperson to get food. The social roles objection is motivated by a desire to explain the intuitive belief that these 'exploitative' actions are not actually wrong. It does this by explaining why the 'exploited' agent (the salesperson) is not treated as a mere means and, consequently, why the actions that we perform against these agents are actually permissible on Kantian grounds. The objection considered below thus helps to clarify the scope of permissible and impermissible actions, according to Kant's formula of humanity.
}

as a mere means and is exploitative and wrong, according to Kant. However, suppose that you are playing the social role of a boxer and we are in the context of a boxing ring. In this case, the otherwise exploitative act (punching you in the face to reduce my stress levels) becomes morally acceptable. This is because, by agreeing to play the social role of a boxer, you have tacitly consented to being physically attacked within the context of the boxing ring. As you have agreed to this treatment, my punching you in the face is legitimate and anticipatable and is therefore not exploitative. ${ }^{16}$

My opponents could apply a similar argument to virtual murder. By playing the game, victims are agreeing to play the role of a game opponent. ${ }^{17}$ By playing the social role of a game opponent, victims tacitly consent to any activities that result from playing this social role. In notably combative games (such as World of Warcraft) where the risk of virtual death is high, agreeing to play the social role of a game opponent entails that victims have tacitly consented to violent treatment by other players. In these cases, virtual murder becomes a legitimate and anticipatable act and is no longer exploitative (as I claim). ${ }^{18}$

For the above argument to work, victims must be aware of the risk of virtual murder (it must be anticipatable), understand that virtual murder is possible (it must be legitimate), and have chosen to continue playing the role of a game opponent. It is only if this can be shown that the social roles objection can refute my claim that virtual murder is exploitative. In what follows I argue that the social roles objection is unsuccessful as it relies on a problematic claim that victims agree to play the social role of game opponents.

To understand why this claim is problematic, let us unpick what would be required for victims to agree to play the social role of game opponents. To agree to play this role, victims must (a) know what social role they are playing

\footnotetext{
$\overline{16}$ Some may retort that boxers actually give explicit consent rather than tacit consent. I argue that, whilst boxers do give explicit consent to take part in matches, they only give tacit consent to their opponent's strategies and actions. This is because a boxer could only explicitly consent to their opponent's actions if they knew every specific action and/or move that their opponent was going to perform. This demands too much.In arguing that boxers give tacit consent (and are thus not exploited), I am highlighting a difference between competitive sports and MMORPGs (in which, actions can lack tacit consent). This challenges McCormick's aforementioned claim that there is no distinction between the two types of game.

17 This is a variant of the arguments considered in the "Roleplaying" subsection of "The moral status of MMORPGs" subsection.

18 Importantly, the social roles argument challenges my previous argument that victims cannot tacitly consent to virtual murder because they lack knowledge of relevant norms and moral standards. According to the social roles argument, the victim is aware of these norms and standards as, by agreeing to play the social role of a game opponent, victims do know (and tacitly consent) that others may harm or kill them.
} 
(game opponents), (b) have a clear understanding of the relationship between themselves and those using them as a means, and (c) have all the information needed to make an informed, autonomous decision regarding whether they wish to continue being used as a means in this context.

Conditions $\mathrm{b}$ and $\mathrm{c}$ cannot be met in the virtual murder examples mentioned in the last section. Player Two (the victim) cannot fully understand the relationship between themselves and those using them as a means (player one) because, in the cases considered, when player one performs virtual murder, they are performing an opportunistic or deviant act which uses player two in new and unexpected ways. Thus, whilst player two could understand that they are a game opponent to player one, they cannot be expected to understand that they are a potential victim for player one. Similarly, in the cases of virtual murder considered, player two does not have all the information needed to make an informed, autonomous decision regarding whether they wish to continue being used as a means in this context. This is because the context (virtual murder) is itself deviant and opportunistic so there is no background knowledge or norms that player two can draw on in order to make an autonomous decision about whether to continue playing with the risk of virtual murder.

If the above is correct, then player two (the victim) does not meet the conditions for playing the social role of a game opponent. If so, then the social roles objection fails to show that victims play the role of game opponents and, in doing so, offer informed, tacit consent to virtual murder.

\section{Conclusion}

This article has expanded the arguments of Ali (2015) and McCormick (2001) by arguing that a virtual murder in a MMORPG can be wrong (on Kantian grounds) if it exploits the player controlling the victim. To do this, I argued that there are virtual murders that are exploitative because the player controlling the victim does not have the opportunity to tacitly consent to the virtual murder, and I presented case studies which showed this. Because of this lack of tacit consent, these virtual murders violate Kant's formula of humanity, and are wrong on Kantian grounds. I concluded by defending this view against the social roles objection. In rejecting the social roles objection, I argued that victims do not tacitly consent to virtual murder as a result of playing the social role of game opponents.

Acknowledgements Work for this article has been funded by the Arts and Humanities Research Council's Midlands4Cities Doctoral Training Partnership. The article was part of an MA dissertation, but has been amended and expanded. I have greatly benefited from numerous thought-provoking discussions with staff and students within the
University of Birmingham's philosophy department. Particular thanks to Maja Spener for her support of the initial idea, and to Darragh Byrne, Jussi Suikkanen, Jeremy Williams, and Scott Sturgeon for their invaluable feedback, suggestions, and encouragement. Thanks also to Heather Widdows and Clare Chambers for their mentoring and advice. Earlier drafts of this article have been presented at the University of Birmingham's postgraduate seminar, the British Postgraduate Philosophy Association conference, the Oxford Graduate Philosophy conference, and the Video Games and Virtual Ethics 2017 conference. I thank the audiences for their stimulating questions, comments, examples, and suggestions. Particular thanks to Tom Douglas for acting as a respondent during the Oxford Graduate Philosophy conference. Additionally, I would like to thank three anonymous reviewers for Ethics and Information Technology for their detailed, helpful reviews. Finally, thanks go to my friends and family for sending numerous new stories on virtual murder, suggesting novel ways in which I could get virtually murdered, and for offering to virtually murder me.

Funding Funding was provided by Arts and Humanities Research Council with Grant No. AH/L50385X/1.

Open Access This article is distributed under the terms of the Creative Commons Attribution 4.0 International License (http://creativeco mmons.org/licenses/by/4.0/), which permits unrestricted use, distribution, and reproduction in any medium, provided you give appropriate credit to the original author(s) and the source, provide a link to the Creative Commons license, and indicate if changes were made.

\section{References}

Ali, R. (2015). A new solution to the gamer's dilemma. Ethics and Information Technology, 17, 267-274.

Bartel, C. (2015). 'Free will and moral responsibility in video games'. Ethics and Information Technology, 17(4), 285-293.

Chalk, A. (2017) Playerunknown's Battlegrounds player banned for team-killing a team-killer' [online]. Retrieved July 09, 2017 http:// tinyurl.cpm/y6wgz8m9.

Craft, A. J. (2007). Sin in cyber-eden: Understanding the metaphysics and morals of virtual worlds. Ethics and Information Technology, 9(3), 205-217.

Danielson, P. (1992). Artificial morality: Virtuous robots for virtual games. London: Routledge.

Driver, J. (2007). Dream immorality. Philosophy, 82(1), 5-22.

Dunn, J. (2012). Virtual worlds and moral evaluation. Ethics and Information Technology, 14, 255-265.

Goerger, M. (2017). Value, violence, and the ethics of gaming. Ethics and Information Technology, 19, 95-105.

Huizinga, J. (1949). Homo Luden: A study of the play-element in culture. London: Routledge and Kegan Paul.

Kant, I. (2012). [1785]) Groundworks of the metaphysics of morals: Revised Edition. Translated and edited by Mary Gregor and Jens Timmerman. Cambridge: Cambridge University Press.

Kim, T. W., \& Werbach, K. (2016). More than just a game: Ethical issues in gamification. Ethics and Information Technology, 18(2), 157-173.

Luck, M. (2009). 'The gamer's dilemma: An analysis of the arguments for the moral distinction between virtual murder and virtual paedophilia. Ethics and Information Technology, 11, 31-36.

Mason, D. (2014). Video games, theater, and the paradox of fiction. The Journal of Popular Culture, 47(6), 1109-1121.

McCormick, M. (2001). Is it wrong to play violent video games?. Ethics and Information Technology, 3, 277-287. 
Ostritsch, S. (2017). The amoralist challenge to gaming and the gamer's moral obligation. Ethics and Information Technology, 19(2), $117-128$.

Pallikkathayil, J. (2010). Deriving morality from politics: Rethinking the formula of humanity. Ethics, 121(1), 116-147.

Parfit, D. (2011). On what matters: Volume one, Oxford: Oxford University Press.

Patridge, S. (2011). The incorrigible social meaning of video game imagery. Ethics and Information Technology, 13, 303-312.

Patridge, S. (2013). Pornography, ethics, and video games. Ethics and Information Technology, 15, 25-34.

Statista (2015) Number of World of Warcraft (WOW) subscribers from 2015 to 2023 (in millions). Retrieved July 04, 2018 from https ://www.statista.com/statistics/276601/number-of-world-of-warcr aft-subscribers-by-quarter/.

Waddington, D. I. (2007). Locating the wrongness in ultra-violent video games. Ethics and Information Technology, 9, 121-128.
Wolf, M. J. P. (2003). Virtual morality: Morals, ethics, and new Media. New York: Peter Land Publishing.

Wolfendale, J. (2009). Virtual harm and attachment. Australian Institute of Family Studies, 21, 9-11.

Young, G. (2013) Ethics in the virtual world: The morality and psychology of gaming. Durham: Acumen Publishing Ltd.

Young, G. (2015). Violent video games and morality: A meta-ethical approach. Ethics and Information Technology, 17, 311-321.

Publisher's Note Springer Nature remains neutral with regard to jurisdictional claims in published maps and institutional affiliations. 